\title{
Miranda
}

Revue pluridisciplinaire du monde anglophone /

Multidisciplinary peer-reviewed journal on the English-

speaking world

17 | 2018

Paysages et héritages de David Bowie

\section{Didon et Enée au Festival d'Aix-en-Provence (juillet 2018) : Purcell et la révolte des femmes de Chypre}

\author{
Elisabeth Rallo Ditche
}

\section{OpenEdition}

Journals

Édition électronique

URL : http://journals.openedition.org/miranda/13783

DOI : 10.4000/miranda. 13783

ISSN : 2108-6559

Éditeur

Université Toulouse - Jean Jaurès

\section{Référence électronique}

Elisabeth Rallo Ditche, «Didon et Enée au Festival d'Aix-en-Provence (juillet 2018) : Purcell et la révolte des femmes de Chypre », Miranda [En ligne], 17 | 2018, mis en ligne le 01 octobre 2018, consulté le 16 février 2021. URL : http://journals.openedition.org/miranda/13783; DOI : https://doi.org/10.4000/

miranda. 13783

Ce document a été généré automatiquement le 16 février 2021.

\section{(c) $(1) \odot$}

Miranda is licensed under a Creative Commons Attribution-NonCommercial-NoDerivatives 4.0 International License. 


\section{Didon et Enée au Festival d'Aix-en- Provence (juillet 2018) : Purcell et la révolte des femmes de Chypre}

\section{Elisabeth Rallo Ditche}

Didon et Enée, 2018

Opéra en un prologue et trois actes

Livret de Nahum Tate

4 Nouveau Prologue écrit par Maylis de Kerangal, interprété par Rokia Traoré

5 Nouvelle production du Festival d'Aix-en-Provence et de son Académie.

6 En coproduction avec le Théâtre du Bolchoï - Théâtre Académique d'État de Russie

7 Vincent Huguet Metteur en scène

8 Václav Luks. Chef d'orchestre

9 Anaïck Besson Didon

10 Sophia Burgos Belinda

11 Tobias Greenhalgh Enée

12 Lucile Richardot Sorceress et Esprit

13 Fleur Barron 1re sorcière

14 Majdouline Zerari 2e sorcière

15 Seul opéra anglais (grande nouveauté de l'œuvre) composé après Vénus et Adonis de John Blow, Didon et Enée est une œuvre de chambre sur un texte de Nahum Tate, une œuvre unique qui a inspiré tous les autres musiciens anglais (Purcell retourna ensuite à ce qu'on a appelé ses "semi-opéras »). Le sujet avait été porté à la scène des centaines de fois, et ainsi Metastase avait donné une Didon abandonnée qui avait eu un immense succès. La première eut lieu en 1690 (date incertaine), puis il y eut des reprises en 1700 puis en 1704, l'œuvre plongeant ensuite dans deux cents ans d'oubli en tant qu'opéra, 
n'étant plus jouée que sous forme de cantates et de concert. Pour le bicentenaire de Purcell, on reprit Didon et Enée en 1895 au Royal College of Music.

C'est un véritable petit traité des passions: amour, nostalgie, angoisse, désespoir, montrés de façon délicate, se mêlent, comme chez Shakespeare, à un style bouffon. L'œuvre fait entrer l'auditeur dans un univers fantastique délicieux et farfelu, avec des sorcières qui crient des «Ho, ho" et sont méchantes par pur plaisir, jalouses du bonheur d'autrui et surtout de la grande reine de Carthage, tellement belle, amoureuse et aimée. Et pour la mort de Didon, une aria de cinq minutes, troublante et magnifique, emporte le spectateur.

On y trouve aussi un chœur superbe qui commente les passions des personnages, des récitatifs, des airs, des pages instrumentales et des danses. Chaque acte commence par une ouverture instrumentale, la première étant plus développée, à la française avec chromatisme ; et chaque acte comporte également un grand air avec basse obstinée (ground).

Auréolé de son prestige d'ancien assistant de Patrice Chéreau, Vincent Huguet a voulu changer la donne et rendre l'opéra " contemporain ». Il est vrai que Nahum Tate avait fait de même avec Virgile: son livret apporte des modifications à la source antique, mineures ou plus importantes (ainsi, c'est Belinda, la suivante, nom à la mode à l'époque, qui joue le rôle d'Anna, la sœur de Didon chez Virgile). Ces transformations répondent au contexte, politique, culturel, esthétique de l'époque et aux nécessités du genre (passage d'un récit, long, à un livret, texte de forme dramatique, court). La magicienne et les sorcières, personnages essentiels du théâtre de l'époque baroque, comme de celui de Shakespeare, remplacent les dieux de l'épopée dans le déclenchement de l'orage et le complot contre Didon. C'est l'Esprit maléfique de la Magicienne qui intervient en prenant l'apparence de Mercure pour rappeler sa mission à Enée. Le merveilleux épique est remplacé par le fantastique baroque, on joue avec le sérieux et le grotesque. La hiérarchie des rôles d'Enée et de Didon est inversée. Alors que l'Énéide place le destin d'Enée au premier plan et que Didon n'apparaît que comme un des obstacles éventuels dans la réalisation de sa destinée, le livret est centré sur le personnage de la reine, son amour et son abandon. Enée devient un rôle secondaire et paraît très falot face à Didon : il ne chante pas d'air à proprement parler. La relation entre les deux héros est transformée. Le livret change la relation ambiguë d'Enée et Didon en une relation amoureuse classique. Enée déclare son amour à Didon comme un amoureux traditionnel, mais l'union des deux amants n'a plus lieu dans la grotte : elle est censée avoir lieu à la fin de l'acte I, la grotte devenant le lieu du complot de la magicienne et des sorcières contre Didon. La séparation des deux amants prend une forme très différente : Enée paraît devant Didon sincèrement brisé et lui propose par amour de braver les ordres des dieux et de rester, choisissant l'amour. Mais Didon ne l'entend pas ainsi, le traitant d'hypocrite et le chassant brutalement. Enfin, la mort de Didon est évoquée de manière très différente : à la mort spectaculaire dans les flammes du bûcher, le livret substitue un doux abandon à une langueur mortelle qui escamote le suicide. Elle meurt d'amour, au sens propre. Avec les changements apportés par rapport à Virgile, le livret de Nahum Tate montre chez les deux héros le triomphe des intérêts individuels sur les intérêts collectifs et politiques. Enée serait prêt à renoncer à la mission imposée par les dieux de fonder une nouvelle cité (impensable pour l'Enée de Virgile), seul le refus de Didon l'en empêchant. De même, la passion individuelle l'emporte chez Didon. C'est en tant que femme trahie et blessée dans son orgueil qu'elle 
refuse la proposition d'Enée, au détriment des intérêts de Carthage, incarnés par Belinda et la Cour. En s'abandonnant à la mort, elle oublie ses devoirs de reine et voue Carthage à la destruction. Le livret de Nahum Tate développe ainsi un véritable réquisitoire contre la passion amoureuse, ruine des intérêts politiques. Il dépasse les stéréotypes de genre imposés par le récit virgilien, opposant un féminin faible, voué par nature à céder aux passions, à un masculin rationnel et positif faisant triompher les intérêts collectifs de la Cité sur les passions et les sentiments individuels.

Mais Vincent Huguet modifie encore plus la perspective, aboutissant à une forme de réécriture du récit mythique. Il entend proposer une version méditerranéenne et même africaine de l'Opéra. En guise de Prologue (celui de Purcell étant perdu), un texte écrit par la romancière Maylis de Kérangal, une séquence liée à l'exil de Didon depuis Tyr, racontée par l'historien Justin dans ses Histoires Philippiques (XVIII, 5) : l'enlèvement par Didon, lors d'une escale à Chypre, d'environ quatre-vingts jeunes filles consacrées au culte d'Aphrodite, destinées à devenir les épouses de ses compagnons d'exil pour peupler la ville qu'elle veut fonder. Sur scène, ce texte de Maylis de Kérangal est récité par Rokia Traoré, chanteuse, compositrice et guitariste malienne. Vincent Huguet imagine que ce groupe de jeunes filles enlevées sur les ordres de Didon va comploter par vengeance contre elle et causer sa ruine, remplaçant ainsi la Magicienne et les sorcières du livret qui n'agissaient que par pur plaisir de faire le mal. Dans cette nouvelle mise en scène, l'épisode de l'enlèvement des quatre-vingts jeunes filles à Chypre et son exploitation dans la ruine de Didon, suscite une réflexion sur la faute politique. La décision de l'enlèvement relève d'une préoccupation politique, qui rappelle celle de l'enlèvement des Sabines: comment permettre le développement démographique d'une nouvelle cité en fournissant des épouses aux guerriers. Cet enlèvement, qui prive Didon de son image d'innocente victime, n'est pas seulement responsable de la destruction de son bonheur individuel, mais aussi de celle de la Cité. Cette décision apparaît doublement coupable: elle légitime l'usage de la violence et bafoue les valeurs morales, puisque Didon viole tout autant les lois de l'hospitalité (elle a été bien accueillie à Chypre, ce que rappelle le Prologue) que les lois religieuses et culturelles de l'île (le rite de la prostitution sacrée). Les conséquences de cet acte politique - la ruine de la Cité au lieu de sa prospérité et de sa gloire - se révèlent contraires à ses visées. Didon ne semble d'ailleurs pas mourir d'amour, elle répond de ses actes contre les femmes de Chypre. C'est cette même femme de Chypre qui raconte le passé et qui a été mise en esclavage qui vient tendre le poison à Didon. Cette dernière ayant trahi la cause des femmes par la fondation même de Carthage, elle doit payer, en tant que reine et en tant que femme.

Le Prologue de la romancière, qui a traité de la migration dans son livre À ce stade de la nuit, est un travail qu'elle définit comme " une mise en orbite de l'opéra ", et qui plonge dans le passé de la reine, mariée de force à son oncle, ce dernier étant ensuite tué par son frère qui décide de faire de sa sœur sa maîtresse. Prise au piège, la princesse phénicienne - «belle, grande, solitaire $»^{1}-$ s'enfuit, décide de fonder sa propre ville en embarquant avec elle des captives qu'elle offre à ses compagnons et qui serviront à peupler cette Carthage qu'elle veut fonder. Elle reproduit à son tour la violence qu'elle a subie avec ses esclaves qui, elles aussi, réclameront vengeance. Vincent Huguet déclare dans une interview pour le Festival d'Aix n'avoir jamais cru à la mort de Didon par chagrin d'amour: "Elle meurt d'autre chose». Et Maelys de Kérangal pense qu'Enée est « un réfugié de guerre, comme de nos jours les personnes qui fuient Alep. Et 
Didon, une réfugiée politique qui fuit une dictature, puisque son frère prend le pouvoir, fait tuer son mari. »

21 Les décors d'Aurélie Maestre sont destinés à cacher la mer, installant un mur entre cette mer invisible et le public, un mur de pierres qui s'écroule et que les femmes révoltées marquent de leurs signes. Le bateau (ou plutôt un morceau de la poupe) ne peut apparaître et doit descendre du ciel. Les costumes de Caroline de Vivaise ont des couleurs ternes et neutres, fort peu méditerranéennes (tout comme l'atmosphère générale de la mise en scène), et rappellent les costumes qu'affectionnait Chéreau. Des soldats, des femmes en costumes intemporels, les chœurs des Carthaginois, en vêtements de dockers plus que de marins, rapprochent l'action du public contemporain. Le jour n'apparaît jamais dans sa lumière propre et le bruit de l'orage est très fort, au point de rendre ardue l'écoute de la musique.

Vincent Huguet a-t-il procédé comme Nahum Tate ? Pas tout à fait. Le livret anglais est une création et une réécriture de textes anciens. La mise en scène est une transposition. Le livret de Tate est entièrement nouveau et les personnages sont modifiés, comme le spectateur l'entend dans leurs propos et le voit dans leurs actes. Les sorcières venues tout droit de Shakespeare introduisent un autre univers dans l'opéra de Purcell et surtout une autre tonalité, une dimension burlesque. Vincent Huguet ne modifie rien du livret mais suggère autre chose par la mise en scène : ainsi le chœur, qui commente les actions et soutient la reine de Carthage, se fait hostile dans ses gestes et dans ses intentions, ces dernières étant évoquées par les graffitis sur le mur ou par certaines attitudes corporelles. Enée ne chasse pas mais tue une des manifestantes. Didon n'est pas aimée du peuple, ayant provoqué la révolte de ces femmes embarquées de force pour être données à ses compagnons. Les sorcières ne sont plus méchantes par plaisir et par jalousie vis-à-vis des amants heureux, elles militent pour la cause des femmes et n'ont plus rien de drôle. L'atmosphère elle-même est affectée par cette transposition, la douceur ou la cruauté des faits et des personnages étant comme occultées par le problème politique qui vient de loin, d'un avant qui pèse lourdement sur les êtres. Les paroles chantées ne sont plus en adéquation avec ce qu'on voit sur scène, et, comme cela se produit bien souvent, le spectateur est contraint en permanence de s'efforcer de suivre le propos du metteur en scène. D'où une impression de malaise et de torpeur pour un opéra si court et si brillant, cette impression d'obscurité qui plane sur la représentation tout entière. Le projet de cette transposition est loin d'être inintéressant, mais la question de son aboutissement laisse songeur. À vouloir trop forcer le spectateur à rapprocher deux mondes et deux époques, on l'éloigne de l'œuvre.

Peut-être eût-il été préférable, en lieu et place du Prologue choisi, de laisser la parole à un poète :

Maintenant le vent est muet

Et muette la mer ;

Tout se tait ; mais je crie

Le cri, seule, de mon cœur,

Cri d'amour, cri de vergogne,

De mon cœur qui brûle

Depuis que je t'ai vu, que tu m'as regardée

Et je ne suis plus rien qu'objet débile.

Je crie, et brûle sans répit mon cœur,

Depuis que je ne suis plus rien 
Que chose en ruine, abandonnée.

(Giuseppe Ungaretti - Extrait de Chœurs décrivant des états d'âme de Didon)

24 Reste la musique de Purcell, quant à elle inchangée, prodigieusement séduisante et aboutie, qui console et éclaire, qui émeut et nous « prend comme une mer »...

\section{NOTES}

1. Prologue

\section{INDEX}

Keywords : Purcell, opera, Festival of Aix-en-Provence, staging, transposition, rewriting Mots-clés : Purcell, opéra, Festival d'Aix-en-Provence, mise en scène, transposition, réécriture Thèmes : Music

\section{AUTEURS}

\section{ELISABETH RALLO DITCHE}

Professeur émérite de Littérature Comparée

Aix Marseille Université

elisabeth.rallodi@free.fr 